\title{
Investigation into Physical and Mechanical Properties of Few Selected Chicken Feathers Commonly Found In Nigeria
}

\author{
S.O. Adetola ${ }^{1}$, A.A. Yekini ${ }^{2}$ and B.S. Olayiwola ${ }^{3}$ \\ ${ }^{I}$ Department of Mechanical Engineering, Ladoke Akintola University of Technology, Ogbomoso, Nigeria. \\ ${ }^{2}$ Department of Mechanical Engineering, Ladoke Akintola University of Technology, Ogbomoso, Nigeria. \\ ${ }^{3}$ Department of Mechanical Engineering, Ladoke Akintola University of Technology, Ogbomoso, Nigeria.
}

\begin{abstract}
This paper studied the use of waste chicken feather as reinforcement in cement bonded composites. Several panels were fabricated consisting of ground feather, cement, river sand and some chemical additives. The properties of the panels were tested after curing and were found to have improved. The moisture content on dry basis was found to be between $15.74 \%$ and $19.51 \%$. The hardness was found to be between 17 and 28.1; 20 and 30 for both exotic white and local chicken feathers, it increased rapidly at lower volume fraction $\left(V_{F}\right)$ of feather and with further significant increase in feather $V_{F}$ gave little increment in hardness value. The tensile strength and strain were found to be inversely proportional to volume fraction while the Young's modulus was proportional to volume fraction up to 0.20 and inversely proportional at $V_{F}$ above this value.
\end{abstract}

Keywords: Cement, Chicken feather, Composite, Feather fibre, Reinforcement,

\section{Introduction}

Chicken feathers are common part of chicken which acts as a protective covering for birds, protecting them from cold, rain, sun and injury. It is important for the feathers to be relatively broad, with a web of good firm texture, a strong shaft, the barbs, barbles and the barbicels closely and tightly knitted together. Chicken feathers are waste products of the poultry industry. Billions of kilograms of waste feathers are produced annually by poultry processing plants thereby causing a serious solid waste problem [1], [2]. The old processes of disposing chicken feathers per year are costly and difficult. They are used as low quality animal feeds, burnt in incinerators thereby causing pollution of the environment. These methods are restricted or generate green house gasses that are pose danger to the environment.

Chicken feathers are made up of fibre and quill, the quill being the stiff central core with hollow tube. Both the quill and fibre are made up of keratin (an insoluble and highly durable protein found in horns, hair, animal hoofs, e.t.c.) [3],[4]. Keratin consists of amino acids but largely made up of crytine, lysine, proline and serine [5],[6]. These amino acids tends to cross-link with one another by forming disulphide or hydrogen bonds resulting in fibres that are tough, strong, light weight and with good thermal and acoustic insulating properties [4],[7]. The unique characteristics of keratin have prompted interest in investigating the use of waste chicken feathers for a number of potential applications. Unfortunately, as a result of low volume requirements of these products, they have not significantly reduced the volume of waste feathers generated each year.

The US Department of Agriculture [8] developed the technology for separating chicken feathers into fibre and quill fractions [9]. This development created a way for the use of chicken feather fibre as reinforcement in composite products. A simple, practical way to include poultry feather into composite boards is to bind them with Portland cement. Simplified studies on this aspect of feather utilization have been reported [10]. However, if this could be proven possible, it could offer an affordable new building material with both economic and environmental advantages.

[11] in his work, made use of polymer as binding material for the composite constructed from chicken feather material but this paper reports on the use of waste chicken feather as reinforcement in cement as bonding agent which will result in the production of low cost and durable building materials suitable for tropical conditions. 


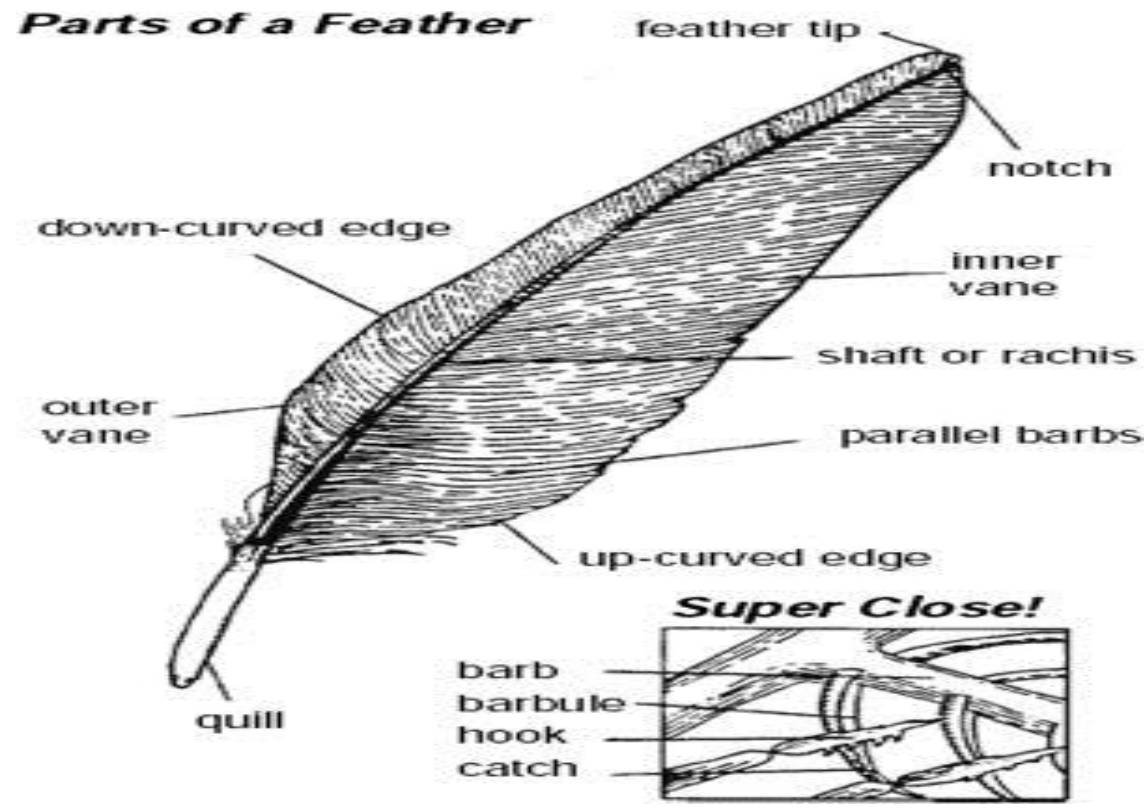

Figure1: A typical chicken feather

\section{Materials and Methods}

Waste chicken feathers were obtained from Bronco farms located at Oluyole estate, Ibadan, Oyo state, Nigeria. The feathers were washed with polar solvent (ethanol) to remove blood, manure and extraneous materials. The feathers were then spread on a sack and dried at room temperature.

Processing involved grinding of feather samples with Wiley milling machine and the powder was sieved out which was stored at room temperature. The composite was constructed using ordinary Portland cement as the binding material, calcium chloride was used as cement setting accelerator and coupling agent (complax 340) was used to improve the bonding of feathers to the matrix material. River sand screened to pass $1 \mathrm{~mm}$ sieve was washed to remove impurities before mixing. A series of feather-cement composite slab measuring $150 \mathrm{~mm} \times 100 \mathrm{~mm} \times 10 \mathrm{~mm}$ were cast.

Cement-feather composites were made by first mixing the required amount of sand and cement (2:1). Feather powder and coupling agent were then added and mixed thoroughly. Calcium chloride completely dissolved in water was added to the mixture. Additional water was added accordingly to give the required paste that could coat all the feather particles. The mixture was uniformly distributed into the constructed wooden frame $(150 \mathrm{~mm} \times 100 \mathrm{~mm} \times 10 \mathrm{~mm})$ and allowed to cure. Each feather-cement mixture combination in this study was replicated twice.

\section{Results and Discussion}

Determination of moisture content were made on samples of chicken feather for 6 hours and the result was found to be between $15.74 \%$ and $19.51 \%$ which is in accordance with the range given as $16 \%-25 \%$, [11]. The moisture content was found to decrease until it becomes constant. This result shows that chicken feather materials have the ability to absorb moisture from the surrounding. The aspect ratio of the feather was also determined, the diameter was found to be between $34.94 \mu \mathrm{m}$ and $95.54 \mu \mathrm{m}$, the length was found to be between $9387.68 \mu \mathrm{m}$ and $11836.64 \mu \mathrm{m}$. The average diameter and length are $65.30 \mu \mathrm{m}$ and $10476.11 \mu \mathrm{m}$ respectively. The aspect ratio calculated using the average length and diameter is $160.43(\mu \mathrm{m} / \mu \mathrm{m})$.

The hardness of the reinforced material was determined using Schmidt concrete hammer. The hardness value increased at lower volume fraction $\left(V_{F}\right)$ of feather powder inclusion between $(0.05$ and 0.14$)$ and with further increase in $V_{F}$ resulted in little increment in hardness value which implies that lower volume fractions are economical as higher volume fractions gave little increment in hardness value with high input of material and money. The tensile strength was taken as the maximum stress which was determined using universal testing machine (UTM). The results of stress and strain shows that panels with inclusion of chicken feather possess higher stress and strain at lower $V_{F}$ and with further increase in $V_{F}$, there was corresponding decrease in stress and strain values. This also justifies the fact that lower volume fractions of feather should be used. The Young's modulus of the chicken feather fibre $E_{F}$ was found to increase as the $V_{F}$ increases from 0.05 to 0.22 , and falls at higher $V_{F}$. The effective Young's modulus of chicken feather fibre $E_{F-E f f e c t i v e}$ at $V_{F}=0.05$ was 2.65 and at $V_{F}=$ 0.14 and 0.22 , the $E_{F-E f f e c t i v e}$ was 4.26 and 4.49 respectively. At a higher $V_{F}$ of 0.33 which is the highest $V_{F}$ used in this report, the $E_{F-E f f e c t i v e}$ falls to 1.41 . 
Investigation into Physical and Mechanical Properties of Few Selected Chicken Feathers .....

Table 1: Determination of Moisture Content of Exotic White Feather

\begin{tabular}{|lll|}
\hline & Trial l(g) & Trial 2 (g) \\
\hline Weight of pan & 182.30 & 182.30 \\
Weight of Sample & 250.00 & 250.00 \\
Weight of pan + Sample & 432.30 & 432.30 \\
Weight of pan + Sample after 2hours & 410.00 & 410.00 \\
Weight of pan + Sample after 1 hour & 402.50 & 402.50 \\
Weight of pan + Sample after 30minutes & 390.00 & 390.00 \\
Weight of pan + Sample after 30minutes & 389.00 & 389.00 \\
Weight of pan + Sample after 30minutes & 387.30 & 387.30 \\
Weight of pan + Sample after 30minutes & 387.30 & 387.30 \\
Weight of pan + Sample after 30minutes & 387.30 & 387.30 \\
Weight of pan + Sample after 30minutes & 387.30 & 387.30 \\
\hline
\end{tabular}

\section{Exotic (White)}

Initial weight of the sample $=$

Final weight of the sample $=$

Moisture Content $($ dry basis $)=$

Moisture Content of Exotic
$432.30-182.30=250 \mathrm{~g}$ $387.30-182.30=205 \mathrm{~g}$

$$
\frac{W_{w-} W_{o}}{W_{o}} \times 100 \% \frac{250-205}{250} \times 100 \%=18 \% \text { White }(\text { dry basis })=
$$

Table 2: Determination of Moisture Content of Exotic Brown Chicken Feather

\begin{tabular}{|lll|}
\hline & Trial l(g) & Trial 2(g) \\
\hline Weight of pan & 182.30 & 182.30 \\
Weight of Sample & 250.00 & 250.00 \\
Weight of pan + Sample & 432.30 & 432.30 \\
Weight of pan + Sample after 2hours & 415.50 & 415.50 \\
Weight of pan + Sample after 1hour & 405.00 & 405.00 \\
Weight of pan + Sample after 30minutes & 402.80 & 402.80 \\
Weight of pan + Sample after 30minutes & 399.50 & 399.50 \\
Weight of pan + Sample after 30minutes & 393.50 & 393.50 \\
Weight of pan + Sample after 30minutes & 392.30 & 392.30 \\
Weight of pan + Sample after 30minutes & 392.30 & 392.30 \\
Weight of pan + Sample after 30minutes & 392.30 & 392.30 \\
\hline
\end{tabular}

\section{Exotic (Brown)}

Initial weight of the sample $=$

Final weight of the sample $=$
$432.30-182.30=250 \mathrm{~g}$

$392.30-182.30=210 \mathrm{~g}$

Moisture Content of Exotic Brown (dry basis) $=\frac{250-210}{210} \times 100 \%=19.51 \%$ 
Investigation into Physical and Mechanical Properties of Few Selected Chicken Feathers .....

Table 3: Determination of Moisture Content of Local Chicken Feather

\begin{tabular}{|lll|}
\hline & Triall(g) & Trial 2 (g) \\
\hline Weight of pan & 182.30 & 182.30 \\
Weight of Sample & 250.00 & 250.00 \\
Weight of pan + Sample & 432.30 & 432.30 \\
Weight of pan + Sample after 2hours & 410.80 & 410.80 \\
Weight of pan + Sample after 1 hour & 402.30 & 402.30 \\
Weight of pan + Sample after 30minutes & 399.50 & 399.50 \\
Weight of pan + Sample after 30minutes & 398.90 & 398.90 \\
Weight of pan + Sample after 30minutes & 398.60 & 398.60 \\
Weight of pan + Sample after 30minutes & 398.30 & 398.30 \\
Weight of pan + Sample after 30minutes & 398.30 & 398.30 \\
Weight of pan + Sample after 30minutes & 398.30 & 398.30 \\
\hline
\end{tabular}

Indigenous (Cock)

Initial weight of the sample $=$

Final weight of the sample $=$

$432.30-182.30=250 \mathrm{~g}$

Moisture Content of Indigenous Cock (dry basis) =

$$
\frac{250-216}{216} \times 100 \%=15.74 \%
$$

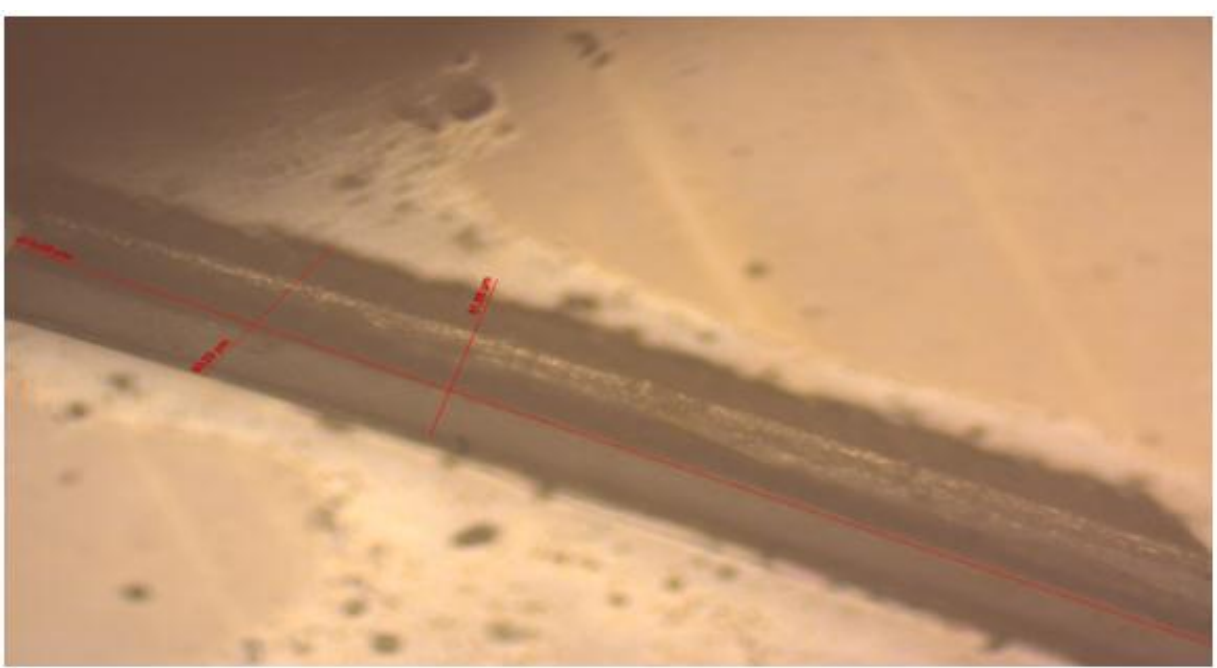

Figure 2: An image of white broiler fibre captured at x50 magnification. 


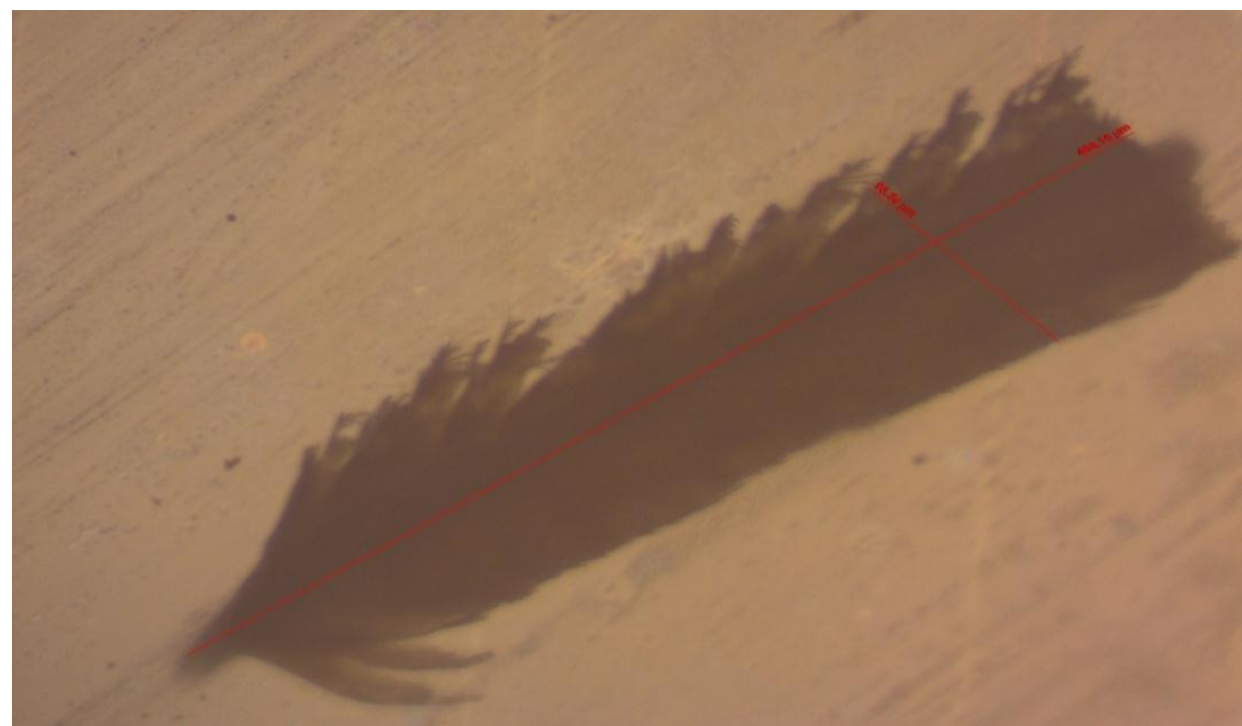

Figure 3: An image of brown layer fibre captured at x50 magnification.

The volume fraction was determined using the equation below: $\frac{\text { Mass of feather particle inclusion }}{\text { Total mass of composite }} \times 100$ 2

The hardness of the reinforced material was determined using Schmidt concrete hammer. The hardness value increased significantly at volume fraction $\left(V_{F}\right)$ between $(0.05$ and 0.15$)$ but further increase in $V_{F}$ resulted in little increment in hardness value which implies that lower volume fractions are economical as higher volume fractions gave little increment in hardness value with high input of material.

Table 4: Results of Hardness Test, Tensile strength and Young's modulus at different volume fraction for Exotic White Feather

\begin{tabular}{|lllc|}
\hline $\begin{array}{l}\text { Volume } \\
\text { Fraction }\left(\boldsymbol{V}_{\boldsymbol{F}}\right)\end{array}$ & $\begin{array}{l}\text { Hardness } \\
\text { Test }\end{array}$ & $\begin{array}{c}\text { Tensile } \\
\text { Strength }\left(\boldsymbol{\sigma}_{\mathbf{c}}\right)\end{array}$ & $\begin{array}{c}\text { Young's } \\
\text { Modulus }\left(\boldsymbol{E}_{\boldsymbol{c}}\right)\end{array}$ \\
\hline 0.05 & 17.0 & 30.5 & 1.13 \\
0.10 & 22.0 & 30.0 & 1.42 \\
0.15 & 25.0 & 30.0 & 1.50 \\
0.20 & 26.0 & 24.0 & 1.85 \\
0.25 & 27.0 & 10.0 & 1.65 \\
0.30 & 28.1 & 7.0 & 1.17 \\
\hline
\end{tabular}

The tensile strength was taken as the maximum stress which was determined using universal testing machine (UTM). The results of stress and strain shows that panels with inclusion of chicken feather possess higher stress and strain at lower $V_{F}$ and with further increase in $V_{F}$, there was corresponding decrease in stress and strain values. This also justifies the fact that lower volume fractions of feather should be used.

Table 5: Results of Hardness Test, Tensile strength and Young's modulus at different volume fraction for Local Chicken Feather

\begin{tabular}{|llll|}
\hline $\begin{array}{l}\text { Volume } \\
\text { Fraction }\left(\boldsymbol{V}_{\boldsymbol{F}}\right)\end{array}$ & $\begin{array}{c}\text { Hardness } \\
\text { Test }\end{array}$ & $\begin{array}{c}\text { Tensile } \\
\text { Strength }\left(\boldsymbol{\sigma}_{\mathbf{c}}\right)\end{array}$ & $\begin{array}{c}\text { Young's } \\
\text { Modulus }\left(\boldsymbol{E}_{\boldsymbol{c}}\right)\end{array}$ \\
\hline 0.05 & 20.00 & 33.00 & 1.80 \\
0.10 & 25.00 & 32.50 & 2.00 \\
0.15 & 28.50 & 32.50 & 2.10 \\
0.20 & 28.50 & 26.0 & 2.45 \\
0.25 & 29.00 & 16.00 & 2.30 \\
0.30 & 30.00 & 10.00 & 1.90 \\
\hline
\end{tabular}


Investigation into Physical and Mechanical Properties of Few Selected Chicken Feathers .....

Table 6: Results of Fibre Young's Modulus and Fibre Effective Young Modulus at different Volume Fractions

\begin{tabular}{|ccc|}
\hline $\begin{array}{c}\text { Volume Fraction } \\
\left(V_{B}\right)\end{array}$ & $\begin{array}{r}\text { Fibre Young's Modulus } \\
\left(E_{B}\right)\end{array}$ & $\begin{array}{c}\text { Fibre Effective Young's Modulus } \\
\left(E_{F} \text { - } \text { Effecme }\right)\end{array}$ \\
\hline 0.05 & 1.84 & 2.65 \\
0.10 & 3.50 & 3.45 \\
0.15 & 5.33 & 4.20 \\
0.20 & 7.26 & 4.46 \\
0.25 & 6.80 & 3.80 \\
0.30 & 0.33 & 1.40 \\
\hline
\end{tabular}

The Young's modulus of the chicken feather fibre $E_{F}$ was found to increase as the $V_{F}$ increases from 0.05 to 0.20 and falls at higher $V_{F}$. The effective Young's modulus of chicken feather fibre $E_{F}-$ Effective at $V_{F}=$ 0.05 was 2.65 and at $V_{F}=0.15$ and 0.20 the $E_{F}-$ Effective was 4.20 and 4.46 respectively. At a higher $V_{F}$ of 0.30 which is the highest $V_{F}$ used in this report, the $E_{F}-$ Effective falls drastically to 1.40

\section{Conclusion}

In conclusion, the study showed that waste chicken feather can be used as reinforcement in cement bonded composites to achieve a better strength and undergo minimum stress up to $14 \%$ feather content. Increasing the proportion of chicken feather above 14\% resulted in significant reduction of Young's modulus, tensile strength and decreased dimensional stability. If the minimum volume fraction could be maintained between $5 \%$ and $14 \%$, future use of chicken feather as reinforcement in cement bonded composite would benefit the poultry industry by reducing environmental pollution, cost of disposing feathers and gain profit from the sale of chicken feathers to the building and construction industry.

\section{References}

[1]. G. Parkinson, Chementator: A higher use for lowly chicken feathers? Chem. Eng. 105, 1998, 21.

[2]. W.F. Schmidt, Innovative Feather Utilization Strategies.1998 National Poultry Waste Management Symposium Proceedings 1998.

[3]. M. Karshan, The chemistry and staining reactions of keratin. J. Dental Research 10, 1930, 181-186.

[4]. W.F. Schmidt, Microcrystalline keratin: from feathers to composite, Proc. Material Research Symposium. products In Wallenberger FT, Weston NE, Ford R, Wool RP, Chawla K. (Eds).Boston, Massachusetts December 2-6, 2002 (U1.5.1-U1.5.5).

[5]. W.H. Ward, C.H. Binkley, S.N. Snell, Amino acid composition of normal wools, wool fractions, mohair, feather, and feather fractions. Feather Textile Research Journal 25, 1955, 314-325.

[6]. B.S. Harrar, E.F. Woods, Soluble derivatives of feather keratin 1. Isolation, fractionation and amino acid composition. Biochemistry Journal, 92: 1963, 8-18.

[7]. A.J. Poole, J.S. Church, M.G. Huson, Environmentally sustainable fibers from regenerated protein. Biomacromolecules 10, 2009, 18.

[8]. USDA Foreign Agricultural Service, Philippine Poultry and Products Annual 2005. Global Agriculture Information Network. Manila, October 2005. pp10.

[9]. G. Gassner III, W.F. Schmidt, M. Line, C. Thomas, R. Waters, U.S. Patent (5,705,030), 1998.

[10]. S.A. Hamoush, M.M. El-Hawary, Feather fiber reinforced concrete. Concrete International, 16(6): 1994 $33-35$.

[11]. J. W. Kock, Physical and Mechanical properties of chicken feather materials, MS thesis, School of Civil and Environmental Engineering, Georgia Institute of Technology, 2006.

[12]. Menandro N. Acda Philippine Journal of Science 139 (2): 161-166, December 2010 ISSN 0031 - 7683 